\title{
ORTHOPANTOMOGRAPHY AND AGE DETERMINATION USING THIRD MOLAR MINERALIZATION IN A SAMPLE OF EGYPTIANS
}

\author{
$\mathcal{B Y}$ \\ Neven Ahmed Hassan and Nahed A.A. Abo Hamila* \\ Departments of Forensic Medicine, Faculty of Medicine \& Pediatric Odontology*, \\ Faculty of Dentistry, Tanta University, Egypt
}

\begin{abstract}
In the last decade, the number of unidentified cadavers and cases lacking age documentation and therefore requiring age determination has increased. Dental age determination still represents today the most sensitive mean. In the age span of 15-26 years of age the wisdom teeth represent the only teeth still in development and thereby very important for dental age assessment. So, the aim of the present investigation was to detect the chronological age of an individual based on the dental developmental stages of third molars proposed by Demirjian et al. (1973). In this study 380 orthopantomograms of Egyptian patients (214 males and 166 females) with known age and sex were selected for the study. Patients' age ranged from 8 to 26 years. $X$ rays were examined by the second author (N.A.A.), the developmental stage of third molars in both upper and lower arches were detected using method of Demirjian et al. (1973). Data were gathered and SPSS was used for statistical processing. The mean values and standard deviation $\left(S D_{ \pm}\right)$were determined for the ages of respective mineralization stages of each of the four wisdom teeth. Further statistical analysis was performed in order to obtain multiple regression formulae for dental age calculation. The results showed that the mean age at early developmental stages (A-D) was lower in males than in females in all wisdom teeth. On the other hand, the stages from E-G there was earlier development in females in maxillary molars but it was earlier in males in mandibular molars. The full eruption of third molar ( $H$ stage) was earlier in females in the four molars. The greatest correlation coefficient was found between the developmental stages of maxillary molars in females. A strong correlation was found between lower right and lower left molar in females, a similar correlation was found between upper left and lower left third molars in females. The lower correlation coefficient was noticed between antimeres such as upper right and lower right in males. The probability of an individual being older than 18 years in case of fully developed wisdom was $100 \%$ in females when one molar or more were found but it was $66.7 \%$ in males when one molar is present and $100 \%$ when two or more molars were present. Regression analysis was performed in order to obtain regression formulae for dental age prediction.
\end{abstract}




\section{INTRODUCTION}

In the last decade the number of unidentified cadavers and human remains as well as the number of cases lacking age documentation and therefore requiring age determination has increased. This requires age determination, not only for differentiating the juvenile from the adult status in criminal law cases, but also for chronological age estimation in relation to school attendance, social benefits, employment and marriage (Gunst et al., 2003).

Dental findings are important sources of information regarding forensicodontologic determinations to identify a person's age. The problem of determining a subject's age to ascertain whether he can be criminally charged brings to prominence all the methods of investigation which can be used to define a person's biological age. Dental age is an indicator of biological maturity of adolescents. A method for the assessment of dental age was first described by Demirjian is widely used and accepted mainly because of its ability to compare different ethnic groups (Eid et al., 2002). The methodologies used to determine dental age still represent today the most sensitive means (Olze et al., 2003).

Recent years have seen a rapid growth of the need for forensic age estimations.
Such need arises, for example, if no verified information on the age of a person suspected of a criminal offence is available; the issue at question in terms of criminal law is whether the person concerned has reached the age of criminal responsibility and whether general criminal law in force for older juveniles or adults is to be applied (Schmeling et al., 2004).

The eruption and radiological assessment of the mineralization of third molars are the main criteria for dental age estimation of living people involved in criminal proceedings (Andreas et al., 2004).

The development of wisdom teeth occurs within a definite period of time. The correlation of wisdom tooth development and chronological age has been frequently used for several purposes e. g. the start of orthodontic treatment, estimates of age or, for legal and anthropological purposes (Friedrich et al., 2003).

In the age span of 15-26 years of age the wisdom teeth represent the only teeth still in development and thereby very important for dental age assessment. Hence, the aim of the present investigation is to determine the chronological age of an individual, based on the dental developmental stages of third molars in order to provide predictive values for the age to be above or below 18 years. 


\section{MATERIAL AND METHODS}

The evaluated material consisted of 380 orthopantomograms (panoramic radiographs) obtained from files of Egyptian patients (214 males and 166 females) with known age and sex attending faculty of Dentistry, Tanta University. Their ages ranged from 8 to 26 years. Exclusion criteria were presence of medical history, obvious dental pathology on the orthopantomograms and at least one third molar could be seen in orthopantomograms. The study was based on the evaluation of the developmental stages of third molar proposed by Demirjian et al. (1973) for evaluating the mineralization stages of third molars. This classification distinguished 8 stages from $(\mathrm{A}-\mathrm{H})$, four stages of crown (A-D) and four stages for root development (E-H) (Olze et al., 2004).

Stage $\mathrm{A}$ is the beginning of mineralization of separate cusps, stage B begins, after fusion of cusps, stage $C$ beginning of dentinal deposits, stage $\mathrm{D}$ crown formation is completed, stage E the root length is less than the crown height, stage $\mathrm{F}$ the root length is equal to or greater than the crown height, stage $G$ the walls of the root canal are parallel and its apical end is still opened and stage $\mathrm{H}$ the apical formation is completed (Koch et al., 1994).

Each of the 8 stages related to a particular developmental phase is illustrated in figures 1, 2, 3, 4. Panoramic films were examined uniformly by a single investigator (N.A.A.) using an x-ray screen. The developmental stages of upper and lower third molars were assessed and the data were recorded for statistical analysis. SPSS program was used for statistical processing. For each gender group, the mean values and standard deviations ( $\mathrm{SD} \pm$ ) of age were determined according to the respective mineralization stages of each of the four wisdom teeth. Further statistical analysis was performed in 3 order to obtain multiple regression formulae for dental age assessment with the chronological age as independent variable and the third molar developmental stages as dependent variables. Pearson correlation coefficients of male and female ages between different molar teeth were calculated. For the application of the regression formulae one has to take into consideration the gender, the location and number of developed wisdom teeth. Probabilities for an individual to be older than 18 years were also calculated in case of fully developed molars.

\section{RESULTS}

This study was conducted to detect the chronological age of an individual based on the development of third molar. Table (1) shows the mean values and standard deviations of male and female ages at different developmental stages of third molar teeth. It was evident that, at early develop- 
mental stages (A-D), the mean ages of upper right molar, lower right molar and lower left molar teeth were significantly lower in males than females $(11.5 \pm 2.54$ versus $13.85 \pm 4.05$ at $p-0.001),(11.55 \pm 2.46$ versus $13.63 \pm 4.34$ at $\mathrm{p}=0.003)$ and $(11.61 \pm$ 2.98 versus $13.46 \pm 4.27$ at $\mathrm{p}=0.009$ ) whereas males showed insignificant decrease of mean age of upper left molar tooth than females in relation to the same developmental stages (A-D), the values were $12.09 \pm 3.99,13.30 \pm 4.06$ respectively at $\mathrm{p}=$ 0.113 .

On the other hand, at the developmental stages (E-G), males showed insignificant earlier development of both mandibular right and left molar teeth than females (mean values of age $=17.73 \pm 2.12$, $18.24 \pm 3.13$ respectively at $p=0.391)$ and $(17.53 \pm 2.31,18.69 \pm 3.37$ respectively at $\mathrm{p}=0.061$ ) whereas development of both maxillary right and left molar teeth were insignificantly earlier in females than males (mean age $=18.09 \pm 3.10,18.24 \pm 3.63$ respectively at $\mathrm{p}=0.844)$ and $(18.33 \pm 3.26$, $18.56 \pm 3.32$ respectively at $\mathrm{p}=0.760$ ).

In the stage of full development $(\mathrm{H}$ stage) females showed significant decrease in the mean age of development of the four molar teeth than males, where the mean age values in females were $23.42 \pm 2.30,23.54 \pm 2.25,23.54 \pm 2.42$ and $23.62 \pm 2.45$ as regards maxillary right, maxillary left, mandibular right and man- dibular left molar teeth respectively compared to $25.62 \pm 4.99,25.47 \pm 4.99,25.97 \pm$ $4.67,25.92 \pm 4.60$ respectively in males.

Table (2) displays the results of correlation between developmental stages of different molar teeth. There were significant positive correlation coefficients between different variables particularly between contralateral molars than antimeres. The highest correlation coefficient was found between upper right and upper left third molars in females $(r=0.902)$. Also strong correlation was found between lower right and lower left third molars in females $(\mathrm{r}=0.855)$. In addition, a similar strong correlation was found between upper left and lower left molars in females $(\mathrm{r}=0.830)$ and between upper right \&lower right molars in females $(r=0.807)$ and between upper right \&upper left molars in males $(r=0.806)$. The lowest correlation coefficient was obtained between upper right and lower left molars in males (i 0.561).

Taking into account the developmental stages and location of wisdom teeth of both males and females, table (3) revealed the probability for an individual being younger or older than 18 years. It was noted that, at early developmental stages (AD), the probability that a male subject is younger than 18 years is $96.3 \%, 92.2 \%$, $96.7 \%$ and $93.8 \%$ as regards upper right, upper left, lower right and lower left 
molar teeth respectively compared to $83.3 \%, 85.7 \%, 80.8 \%$ and $81.5 \%$ respectively in females. As regard the fully developmental stage ( $\mathrm{H}$ stage), the probability that a male is older than 18 years is $100 \%$ as regards both upper right and lower right molars and is $96.9 \%, 97.4 \%$ as regards upper left and lower left molar teeth respectively, while in females, it is $100 \%$ for all molars.

Table (4) revealed that, the presence of four fully developed wisdom teeth in subjects older than 18 years is $100 \%$ for both males and females. The percentage of an individual less than 18 years of age showing at least one fully developed third molar is zero in females but it was 33.3 in males.

Multiple regression analysis was performed in order to obtain multiple regression formulae for dental age prediction with the chronological age as an independent variable and the third molar developmental stage as dependent variable. The lower left third molar displays significant contribution to the statistical model and the constructed regression formula for all studied subjects is:

$\mathrm{Y}=\mathrm{a}+\mathrm{b} \times$ where $\mathrm{y}=$ age, $\mathrm{a}=10.431$ (constant), $b=1.5$ (constant), $x=$ developmental stage of third molar tooth expressed by numbers as follows: stage $A=1$, stage $B=2$, stage $C=3$, stage $D=4$, stage $E=5$, stage $F=6$, stage $G=7$ and stage $H=8$.
Table (5) provides regression equation for age prediction of males, females and total subjects using different developmental stages of the four wisdom teeth.

\section{DISCUSSION}

Age estimation by means of tooth development has been used over a long period of time, which is an accurate measure of chronological age that seems to be independent of exogenic factors like malnutrition or disease. However, age estimation based on dental methods has shortcomings, especially during adolescence when the third molar is the only variable dental indicator left. A great variation in position, morphology and time of eruption exist. The differences between population, different methodology, and the dissimilarity between observers are other important shortcomings (Gunst et al., 2003).

In this study, in order to overcome some of these shortcomings, the stages proposed by Demirjian et al., (1973) presented a classification distinguishing eight stages of crown and root development (stages A-H) (Olze et al., 2003).

The system avoids any numeric identification of stages and is defined by changes of shape in panoramic views; independent of speculative estimations of lengths therefore, this classification seemed to be the most appropriate for this study. In the 
literature studies dealing with age estimation using third molars as age predictors are scarce (Olze et al., 2003).

In this study, the influence of gender on the development of the third molar expressed a trend for significant earlier development in males than in females in relation to (A-D) developmental stages of right maxillary and both mandibular molars and insignificant earlier development of left maxillary molar in males than females. On the other hand, at the developmental stages (E-G) males showed insignificant earlier development of both mandibular third molars than in females while the reverse was found as regards both maxillary molars as females showed insignificant earlier development than males. This result is in agreement with that of Thorson and Hagg (1991), Mincer et al. (1993), Kullman (1995); Gunst et al. (2003) who had studied the third molar root development in relation to chronological age in Japanese, German and Caucasian populations. Therefore, this result seems to be a unique finding for third molars, since for the other permanent teeth the root development rate is faster in females.

As regards the stage of full eruption $(\mathrm{H}$ stage), significant earlier eruption of all molars was found in females than males. The present finding is in contrast with that obtained by Gunst et al. (2003) who ex- pressed earlier development in males than in females. This difference may be related to different population and genetic factors.

Left-right symmetry in development age of the third molar expressed by the correlation coefficient was found to be higher in both maxilla and mandible particularly in females where the highest correlation coefficient were observed between maxillary molars $(\mathrm{r}=0.902)$ and both mandibular molars $(\mathrm{r}=0.855)$ respectively. While males showed left to right maxillary symmetry only $(\mathrm{r}=0.806)$. This finding may be due to coincident development of the right and left sides of the arch i.e. bilateral symmetry. The present findings go in harmony with that obtained by Mincer et al. (1993), Wilershausen et al. (2001); Solari and Abramovitch (2002).

The probability for an individual being older than 18 years was measured for several possible combinations of fully developed wisdom teeth. Taking into account the location of wisdom teeth, $100 \%$ probability was found for both upper right and lower right molars in males and for all molars in females. However, if the number of fully developed wisdom teeth is considered, $100 \%$ probability of an individual being older than 18 years was found if male subject has two or more fully developed wisdom teeth and if a female has one or more fully developed wisdom teeth. Hence, the present findings answer 
the question whether a person is already reached the age of 18 by high degree confidence and considered as an adult. This finding is substantiated by Garamendi et al. (2005).

An important result supplied by the present study is the formulation of regression equations for age prediction of males, females and total subjects using different developmental stages of the four wisdom teeth that obtained from examination of panoramic radiographs. Hence the availability of these formulae will be helpful in forensic investigations regarding the determination of age of either living subjects or dead ones whom heads or skulls are the only remains available for identification procedures as in cases intentionally dismembered bodies, fire victims, decomposed remains and in bodies severely mutilated by animal scavengers.

By comparison to other populations, Japanese and German populations achieved stages of development (A-D \& E$\mathrm{G})$ at higher ages than Egyptians (13.5-18.7 \&18.5-22) respectively in Japanese males and ( 15-19.3 \&18.6-21.8) respectively in Japanese females and 13.6-16.7 \& 16.621.3 in German males and 14.1-15.7 \& 16.8- 21.7 in German females compared to 11.5- 12.59, 17.53-18.56 in Egyptian males and 13.30-13.85 \& 18.09-18.69 in Egyptian females. With regard to $\mathrm{H}$ stage, it is de- veloped at lower ages than Egyptians (22.7 in Japanese males and 22.4 in Japanese females \&22.7 in German males \& 23.1 in German females) compared to 25.97 in Egyptian males \& 23.62 in Egyptian females. Ethnic differences in the chronology of third molar mineralization have been ascertained between Asian, European and African populations, so these findings should be taken to account when examining members of different ethnic groups.

The obtained outcomes of this study suggest that tooth calcification stages from panoramic radiographs might be clinically useful as a developmental marker of the pubertal and early post pubertal growth periods. This leads to the conclusion that the method devised by Demirjian et al. (1973) which was applied successfully in the study herein may be recommended for evaluation of the mineralization of third molars for purposes of forensic age determination.

This study provides evidence for the assumption that radiographs of the teeth in adolescents and young adults can be used for the age estimation, irrespective of the topography of the wisdom tooth. These results should be compared to data from other populations gained by the same method. The conclusions of this study might be useful in the field of forensic odontology. 
Table (1): Mean age (in years) and standard deviations of different stages of third molar teeth development in both sexes.

\begin{tabular}{|c|c|c|c|c|c|c|}
\hline \multirow{2}{*}{$\begin{array}{c}\text { Stage of } \\
\text { development }\end{array}$} & \multicolumn{2}{|c|}{ Males } & \multicolumn{2}{|c|}{ Females } & \multirow[b]{2}{*}{$\mathbf{t}$} & \multirow[b]{2}{*}{$\mathbf{P}$} \\
\hline & Mean & S.D. \pm & Mean & S.D. \pm & & \\
\hline \multicolumn{7}{|l|}{ Upper right: } \\
\hline$(A-D)$ & 11.50 & 2.54 & 13.85 & 4.05 & 3.468 & 0.001* \\
\hline (E-G) & 18.24 & 3.63 & 18.09 & 3.10 & 1.97 & 0.844 \\
\hline H stage & 25.62 & 4.99 & 23.42 & 2.30 & 2.735 & $0.008 *$ \\
\hline \multicolumn{7}{|l|}{ Upper left: } \\
\hline (A-D) & 12.09 & 3.99 & 13.30 & 4.06 & 1.596 & 0.113 \\
\hline (E-G) & 18.56 & 3.32 & 18.33 & 3.26 & 0.307 & 0.760 \\
\hline H stage & 25.47 & 4.99 & 23.54 & 2.25 & 2.527 & $0.013 *$ \\
\hline \multicolumn{7}{|l|}{ Lower right: } \\
\hline (A-D) & 11.55 & 2.46 & 13.63 & 4.34 & 3.065 & $0.003 *$ \\
\hline (E-G) & 17.73 & 2.12 & 18.24 & 3.13 & 0.862 & 0.391 \\
\hline H stage & 25.97 & 4.67 & 23.54 & 2.42 & 3.322 & 0.001* \\
\hline \multicolumn{7}{|l|}{ Lower left: } \\
\hline (A-D) & 11.61 & 2.98 & 13.46 & 4.27 & 2.686 & $0.009 *$ \\
\hline$(\mathbf{E}-\mathbf{G})$ & 17.53 & 2.31 & 18.69 & 3.37 & 1.897 & 0.061 \\
\hline H stage & 25.92 & 4.60 & 23.62 & 2.45 & 3.229 & $0.002 *$ \\
\hline
\end{tabular}

*Significant

Table (2): Correlation between developmental stages of upper and lower third molars in males and females.

\begin{tabular}{|l|c|c|c|}
\hline \multirow{2}{*}{ Variables } & Upper right & Upper left & Lower right \\
\cline { 2 - 4 } & r & r & r \\
\hline Males: & & & \\
Upper left & 0.806 & & \\
Lower right & 0.582 & 0.597 & 0.649 \\
Lower left & 0.561 & 0.754 & \\
\hline Females: & & & \\
Upper left & 0.902 & & 0.855 \\
Lower right & 0.807 & 0.778 & \\
Lower left & 0.751 & 0.830 & \\
\hline
\end{tabular}

All variables are significant at $\mathrm{p}=\mathbf{0 . 0 0 1}$ 
Table (3): Probability for an individual to be older or younger than 18 years in different developmental stages of third molar teeth.

\begin{tabular}{|c|c|c|c|c|c|c|c|c|c|c|c|c|}
\hline \multirow{3}{*}{$\begin{array}{c}\text { Stage } \\
\text { of } \\
\text { development }\end{array}$} & \multicolumn{4}{|c|}{ Males } & \multicolumn{4}{|c|}{ Females } & \multicolumn{4}{|c|}{ Total } \\
\hline & \multicolumn{2}{|c|}{$<18$ years } & \multicolumn{2}{|c|}{$\geq 18$ years } & \multicolumn{2}{|c|}{$<18$ years } & \multicolumn{2}{|c|}{$\geq 18$ years } & \multicolumn{2}{|c|}{$<18$ years } & \multicolumn{2}{|c|}{$\geq 18$ years } \\
\hline & $\mathrm{n}$ & $\%$ & $\mathrm{n}$ & $\%$ & $\mathbf{n}$ & $\%$ & $\mathbf{n}$ & $\%$ & $\mathrm{n}$ & $\%$ & $\mathbf{n}$ & $\%$ \\
\hline \multicolumn{13}{|c|}{ Upper right: } \\
\hline A-D & 52 & 96.3 & 2 & 3.7 & 40 & 83.3 & 8 & 16.7 & 92 & 90.2 & 10 & 9.8 \\
\hline E-G & 16 & 47.1 & 18 & 52.9 & 18 & 39.1 & 28 & 60.9 & 34 & 42.5 & 46 & 57.5 \\
\hline H stage & $\mathbf{0}$ & 0.0 & 58 & $100.0 *$ & $\mathbf{0}$ & 0.0 & 24 & $100.0 *$ & 0 & 0.0 & 82 & $100.0^{*}$ \\
\hline \multicolumn{13}{|l|}{ Upper left: } \\
\hline A-D & 52 & \begin{tabular}{|l|}
92.2 \\
\end{tabular} & 4 & 7.1 & 48 & 85.7 & 8 & 14.3 & 100 & 89.3 & 12 & 10.7 \\
\hline E-G & 14 & 38.9 & 22 & 61.1 & 18 & 37.5 & 30 & 62.5 & 32 & 38.1 & 52 & 61.9 \\
\hline H stage & 2 & 3.1 & 62 & 96.9* & $\mathbf{0}$ & 0.0 & 26 & $100.0 *$ & 2 & 2.2 & 88 & $97.8 *$ \\
\hline \multicolumn{13}{|c|}{ Lower right: } \\
\hline A-D & 58 & \begin{tabular}{|l|}
96.7 \\
\end{tabular} & 2 & 3.3 & 42 & 80.8 & 10 & 19.2 & 100 & 89.3 & 12 & 10.7 \\
\hline E-G & 16 & 53.3 & 14 & 46.7 & 20 & 40.0 & 30 & 60.0 & 36 & 45.0 & 44 & 55.0 \\
\hline H stage & $\mathbf{0}$ & 0.0 & 70 & $100.0 *$ & $\mathbf{0}$ & 0.0 & 26 & $100.0 *$ & $\mathbf{0}$ & 0.0 & 96 & $100.0^{*}$ \\
\hline \multicolumn{13}{|l|}{ Lower left: } \\
\hline A-D & 60 & 93.8 & 4 & 6.3 & 44 & 81.5 & 10 & 18.5 & 104 & 88.1 & 14 & 11.9 \\
\hline E-G & 18 & 52.9 & 16 & 47.1 & 18 & 34.6 & 34 & 65.4 & 36 & 41.9 & 50 & 58.1 \\
\hline H stage & 2 & 2.6 & 74 & $97.4 *$ & 0 & 0.0 & 26 & $100.0^{*}$ & 2 & 2.0 & 100 & 98.0* \\
\hline
\end{tabular}

*Significant at $\mathbf{p}=\mathbf{0 . 0 0 1}$ 
Table (4): Probability for an individual to be older or younger than 18 years with fully developed third molar teeth.

\begin{tabular}{|c|c|c|c|c|c|c|c|c|c|c|c|c|}
\hline \multirow{2}{*}{$\begin{array}{c}\text { No. of fully } \\
\text { developed }\end{array}$} & \multicolumn{4}{|c|}{ Males } & \multicolumn{4}{c|}{ Females } & \multicolumn{4}{c|}{ Total } \\
\cline { 2 - 12 } molars & \multicolumn{1}{|c|}{$\mathrm{n}$} & $\%$ & $\mathrm{n}$ & $\%$ & $\mathrm{n}$ & $\%$ & $\mathrm{n}$ & $\%$ & $\mathrm{n}$ & $\%$ & $\mathrm{n}$ & $\%$ \\
\cline { 2 - 12 } & 96 & 80.0 & 24 & 20.0 & 90 & 67.2 & 44 & 32.8 & 186 & 73.2 & 68 & 26.8 \\
\hline 0 & 4 & 33.3 & 8 & 66.7 & 0 & 0.0 & 2 & 100.0 & 4 & 28.6 & 10 & 71.4 \\
\hline 1 & 0 & 0.0 & 30 & 100.0 & 0 & 0.0 & 10 & 100.0 & 0 & 0.0 & 40 & 100.0 \\
\hline 2 & 0 & 0.0 & 12 & 100.0 & 0 & 0.0 & 0 & 0.0 & 0 & 0.0 & 12 & 100.0 \\
\hline 3 & 0 & 0.0 & 40 & 100.0 & 0 & 0.0 & 20 & 100.0 & 0 & 0.0 & 60 & 100.0 \\
\hline
\end{tabular}

*Significant at $\mathbf{p}=\mathbf{0 . 0 0 1}$

Table (5): Regression formulae for age prediction of males, females and total subjects based on the developmental stages of the four wisdom teeth.

\begin{tabular}{|c|c|c|c|c|c|c|}
\hline \multirow{2}{*}{ Molar teeth } & \multicolumn{2}{|c|}{ Males } & \multicolumn{2}{|c|}{ Females } & \multicolumn{2}{|c|}{ Total } \\
\hline & $\mathbf{t}$ & $\mathbf{P}$ & $\mathbf{t}$ & $\mathbf{P}$ & $\mathbf{t}$ & $\mathbf{P}$ \\
\hline Upper right(UR) & 0.546 & 0.585 & 0.784 & 0.434 & 0.073 & 0.942 \\
\hline Upper left(UL) & 0.426 & 0.670 & 0.759 & 0.449 & 0.131 & 0.896 \\
\hline Lower $\operatorname{right}(\mathrm{LR})$ & 2.711 & $0.007 *$ & 0.896 & 0.372 & 2.905 & $0.004 *$ \\
\hline Lower left(LL) & 4.540 & $0.001 *$ & 3.899 & $0.001 *$ & 6.063 & $0.001 *$ \\
\hline $\mathbf{r}$ & \multicolumn{2}{|c|}{0.585} & \multicolumn{2}{|c|}{0.660} & \multicolumn{2}{|c|}{0.605} \\
\hline $\mathbf{R}^{2}$ & \multicolumn{2}{|c|}{0.343} & \multicolumn{2}{|c|}{0.435} & \multicolumn{2}{|c|}{0.367} \\
\hline
\end{tabular}

* Significant

Males: $\quad$ age $=11.138+$ UR $(0.133)+$ UL $(-0.128)+$ LR $(0.528)+$ LL $(1.107)$

Females: age $=\mathbf{1 0 . 8 5 9}+$ UR (0.239) + UL (-0.257) + LR (0.240) + LL (1.097)

Total: age $=11.003+$ UR (0.014) + UL (-0.029) + LR (0.442) + LL (1.099) 

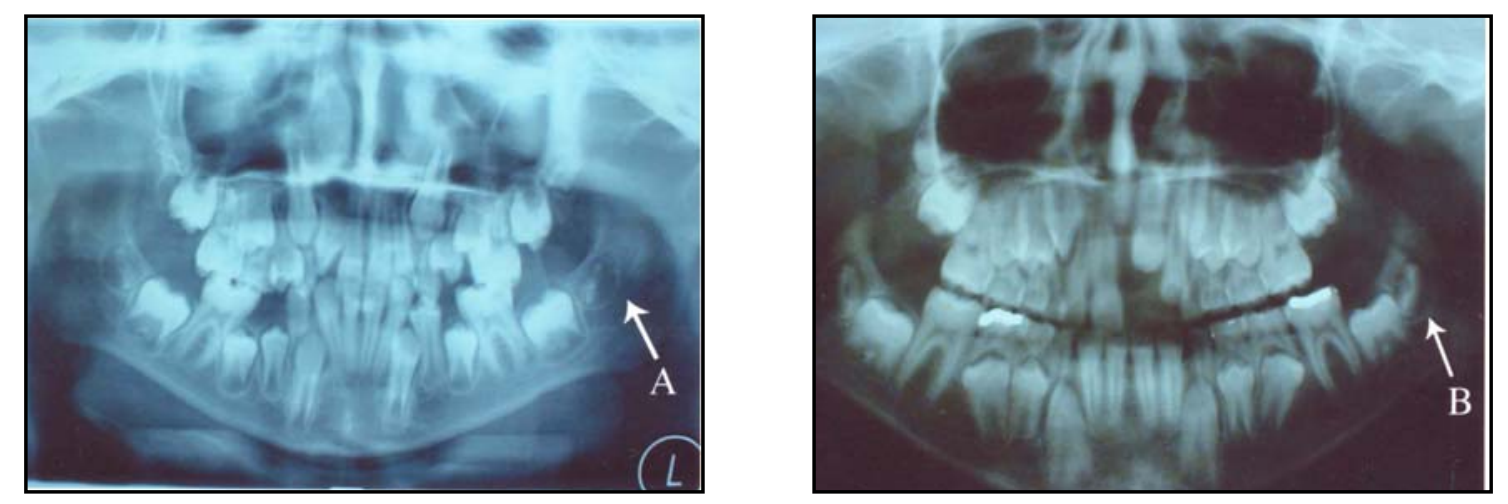

Fig (1): Developmental stages (A\&B) of lower third molars according to Demirjian method.
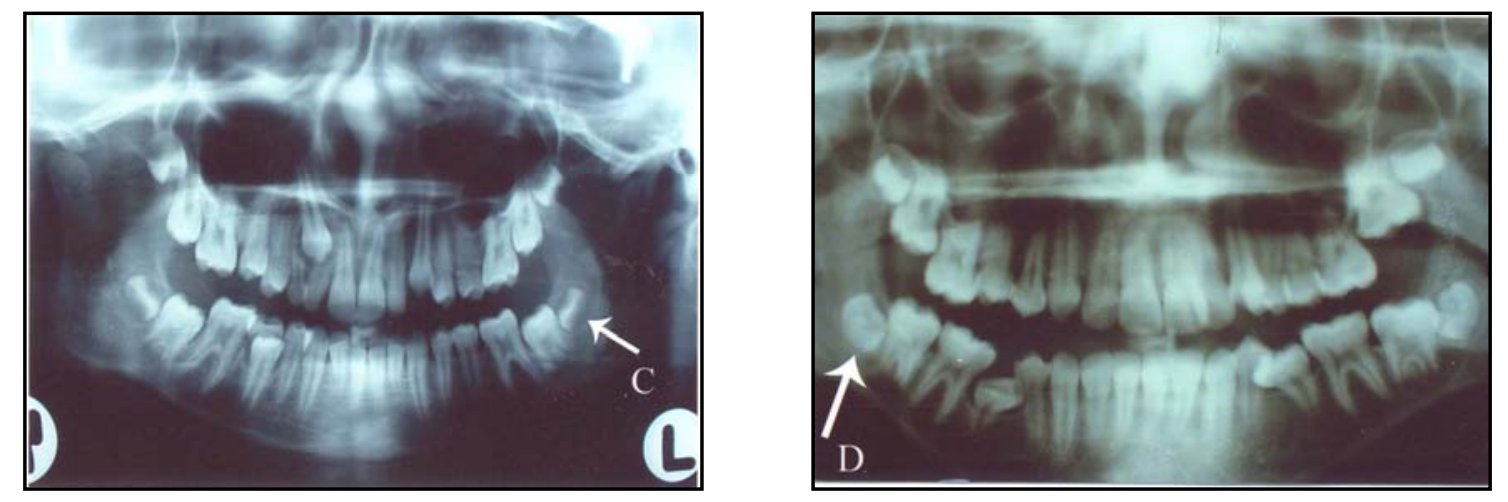

Fig (2): Developmental stages (C\&D) of lower third molars according to Demirjian method. 

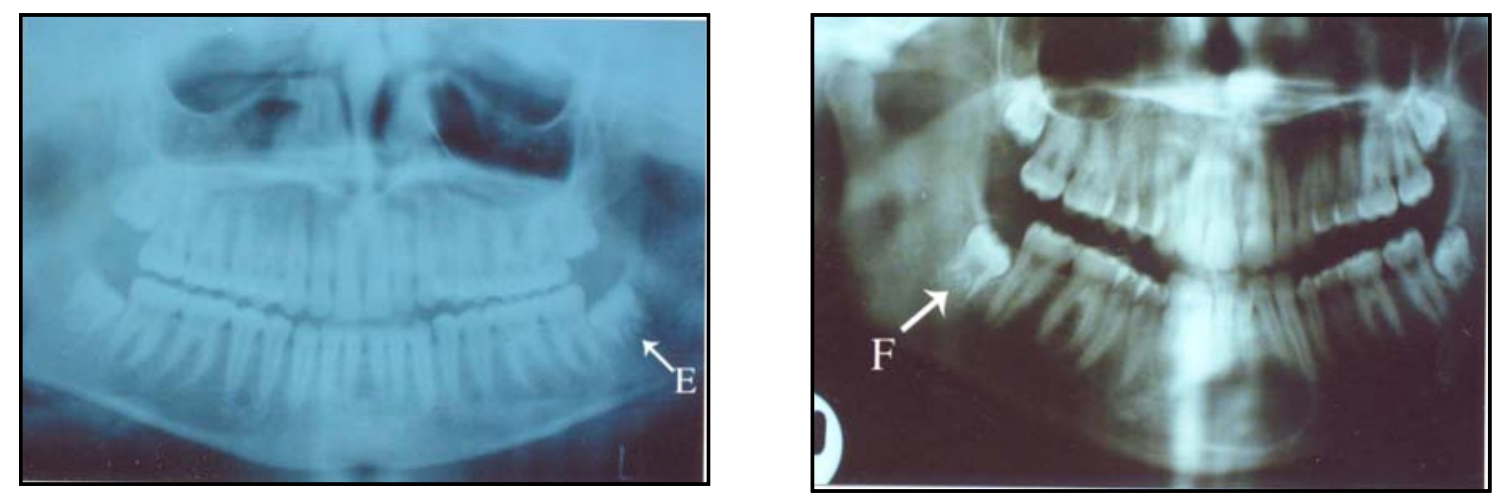

Fig (3): Developmental stages (E\&F) of lower third molars according to Demirjian method.
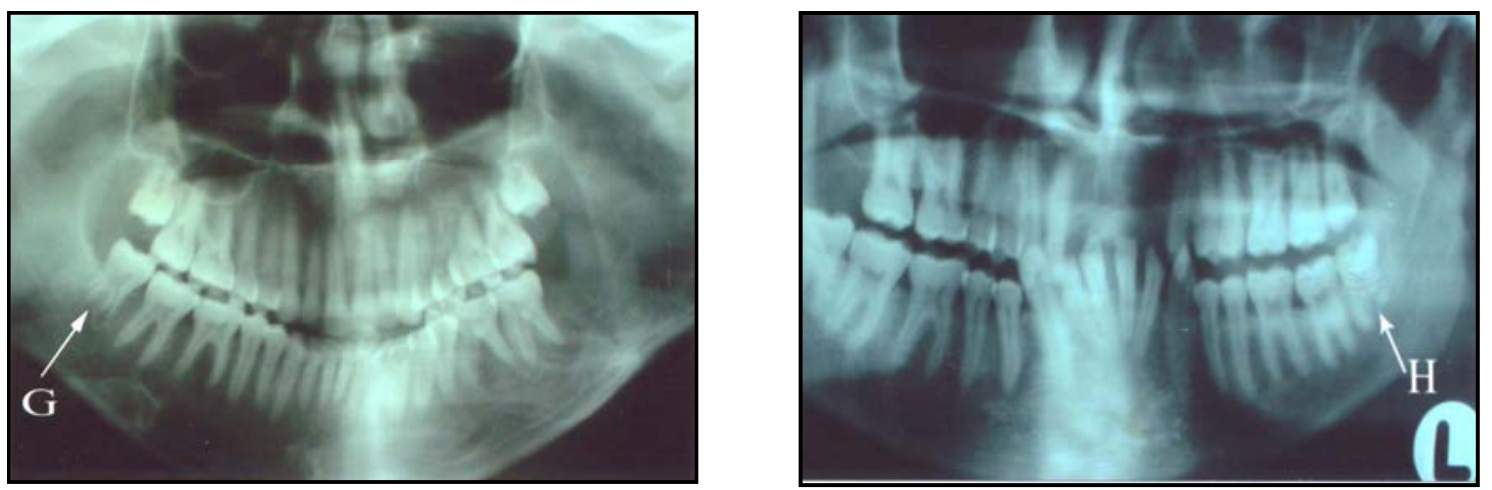

Fig (4): Developmental stages (G\&H) of lower third molars according to Demirjian method. 


\section{REFERENCES}

Andreas, O.; Mahlow, A.; Schmidt, S.; Geserick, G. and Schmeling, A. (2004) : "Radiologically determined DMF index variations for forensic age estimation of young adults". Arch Kriminol., Sep-Oct; 214(3-4): 103-11.

Demirjian, A.; Goldstein, H. and Tanner, T. M. (1973) : "A new dental age assessment". J. Human Biol., 45 : 211 - 227.

Eid, R. M.; Simi, R.; Friggi, M. N. and Fisberg M. ( 2002) : "Assessment of dental maturity of Brazilian children aged 6-14 years using Demirjian,s method". Int. J. Pediatr. Dent., 12(6):423-8.

Friedrich, R. E.; Ulbricht, C.; Ljuba, A. and Baronesse von Maydell. (2003) : "The influence of wisdom tooth impaction on root formation". Ann Anat., Oct., 185 (5) : 481-92.

Garamendi, P. M.; Landa, M. I.; Ballesteros, J. and Solano, M. A. (2005) : "Reliability of the methods applied to assess age minority in living subjects around 18 years old : A survey on a Moroccan origin population". Forensic Sci. Int., 154 (1) : 3-12.

Gunst, K.; Mesotten, K.; Carbonez, A. and Willems, G. (2003) : "Third molar root development in relation to chronological age: a large sample sized retrospective study". Forensic Sci. Int., 136:52-57.

Koch, G.; Modee, T.; Poulsen, S. and Rasmussen, P. (1994) : Dental age estimation. In : Pedodontics A Clinical Approach. Ch. 4., Munsksgard, Copenhagen, P.P. 60-61.

Kullman, L. (1995) : "Accuracy of two dental and one skeletal age estimation method in Swedish adolescents". Forensic Sci. Int., 75: 225-236.

Mincer , H. H.; Harris, E. F. and Berryman, H. E. (1993) : “ABFO study of third molar development and its use as an estimator of chronological age". J. Forensic. Sci., 38 : 379-390.

Olze, A.; Schmeling, A.; Taniguchi, M.; Maeda, H.; Van Niekerk, P.; Wernecke, K. D. and Geserick, G. (2004) : "Forensic age estimation in living subjects : the ethnic factor in wisdom tooth mineralization". Int. J. Legal Med. Jun, 118(3): 170-3.

Olze, A.; Taniguchi, M.; Schmeling, A.; Zhu, B. L.; Yamada, Y.; Maeda, H. and Geserick, G. (2003) : "Comparative study on the chronology of third molar mineralization in Japanese and a German population". Leg. Med., (Tokyo), Mar., 5 Suppi1. 8256-60. 
Thorson, J. and Hagg, U. (1991) : “The accuracy and precision of the third mandibular molar as an indicator of chronological age". Swed. Dent. J., 15:18-22.

Schmeling, A.; Olze, A.; Reisinger, W. and Geserick, G. ( 2004) : "Forensic age diagnostics of living people undergoing criminal proceedings". Forensic Sci. Int. Sep., 10, 144(2-3):243-5. Solari, A. C. and Abramovitch, K. 377-384.
(2002) : "The accuracy and precision of third molar development as an indicator of chronological age in Hispanics". J. Forensic Sci., 47:531-535.

Wilershausen, B.; Loffler, N. and Schuiz, R. (2001): "Analysis of 1202 orthopantomograms to evaluate the potential of forensic age determination based on third molar developmental stages". Eur. J. Med. Res., 6 : 


\title{
نهديد العهر باستخدام تكلس ضرس العقل فى أشعة البانوراها لعينة عن الهصريين
}

\author{
المشتركون فى البحث

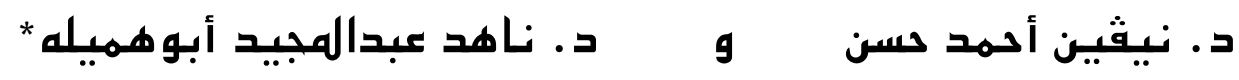 \\ من أقسام الطب الشرعى والسموم بكلية طب طنطا وطب أسنان الأطفال بكلية طب الأسنان* - جامعة طنطا
}

فى الآونة الأخيرة تعددت الحالات التى ينقصها الدليل على العمر الزمنى لذلك فإن الحاجة إلى تحديد العمر قد إزداد. تعرضت معظم الطرق

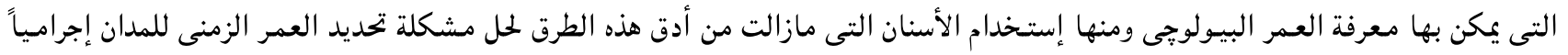

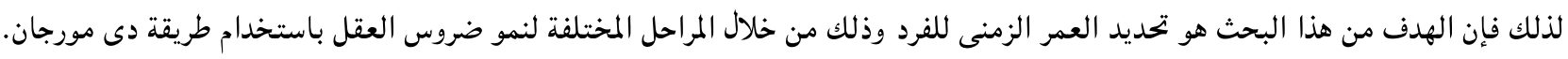

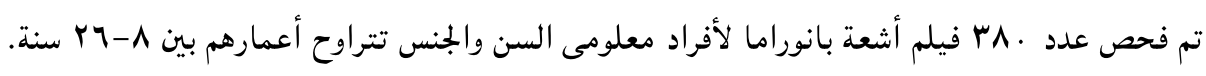

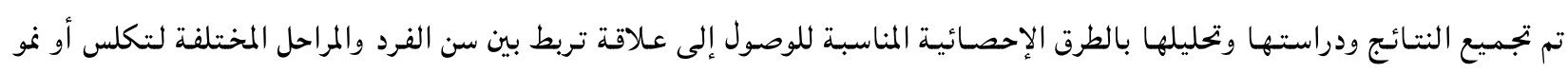

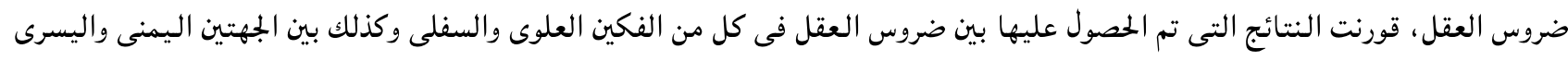
للفك الواحد كما تمت المقارنة بين الذكور والإناث.

$$
\text { أسفرت نتائج البحث عن الآتى : }
$$

تأخر نمو ضروس العقل الأربعة فى الفكين فى الإناث عنه فى الذكور وذلك فى مراحل النمسو المبكرة الخاصة بالتـاج السنى (A-D) بينما

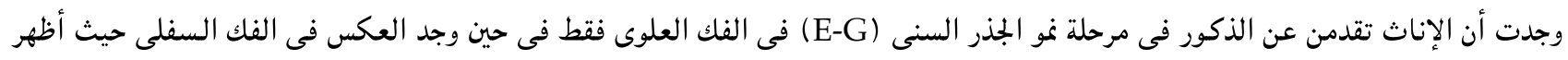
الذكور تطوراً أكبر من الإناث.

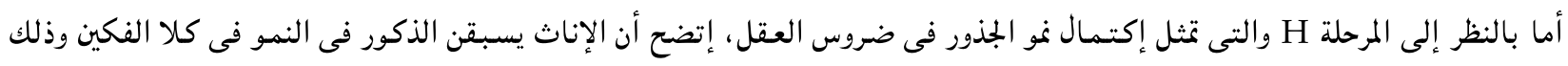

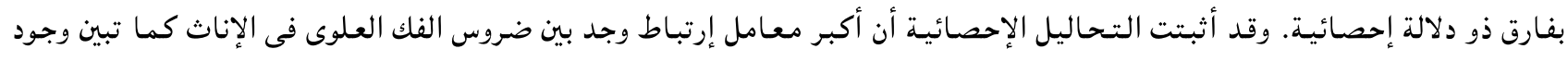

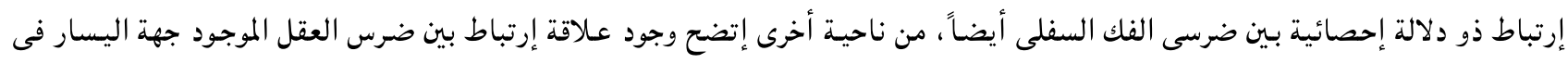

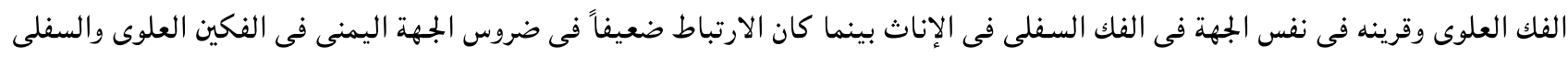
فى الذكور.

كذلك أسفرت النتائج عن أنه فى حالة إكتمال جذور ضروس العقل أى فى المرحلة H فإن نسبة إحتمال كون الفرد أكبر من \ \سنة تكون

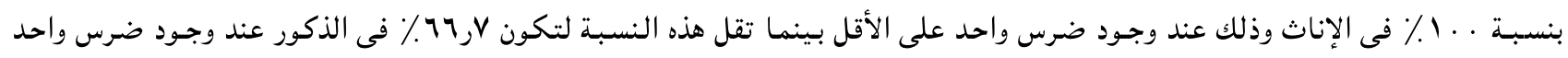
وتصل النسبة إلى . . 1٪ فى الذىكور ولكن عند وجود ضرسان أو أكثر. وأخيراً تم إستخلاص معادلة إحصائية ثابتة لحساب العمر الزمنى للأفراد من خلال معرفة مرحلة تكلس ضروس العقل. 